\title{
Metacognitive awareness of reading strategies of University of Botswana English as Second Language students of different academic reading proficiencies
}

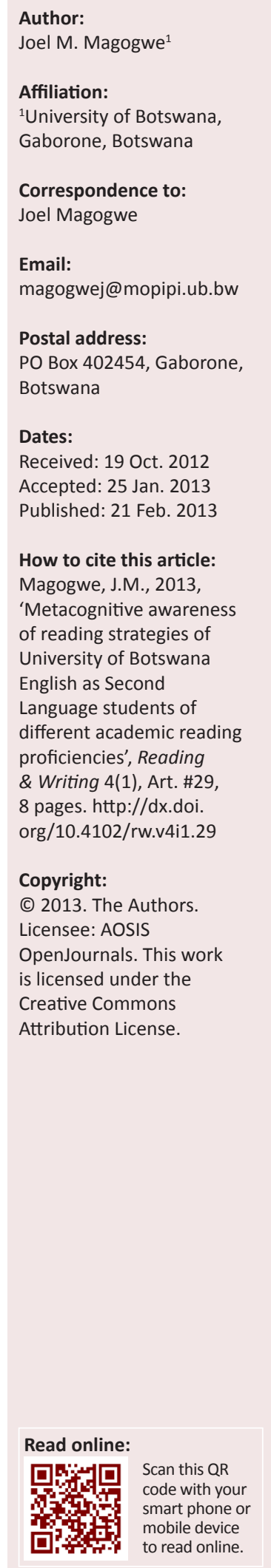

This study explored metacognitive awareness level of University of Botswana students in the Faculty of Social Sciences. It also considered the more recent research focusing on the role of metacognitive awareness in reading and how it relates to proficiency. The following questions are addressed: (1) What are the self-reported reading proficiencies of the University of Botswana students? (2) Are the University of Botswana students aware of their metacognitive reading strategies? (3) What kind of metacognitive reading strategies are frequently used? (4) Is there a difference in metacognitive awareness of reading strategies used by high- and lowproficiency students respectively? The Survey of Reading Strategies Questionnaire (SORS) developed by Mokhtari and Sheorey (2002), and the semi-structured interview technique were used to collect data for this study. The findings indicate that University of Botswana English as Second Language (ESL) students reported high reading proficiency and high use of metacognitive strategies, but there was no vast difference in terms of proficiency. Students who reported their proficiency as high had an edge over low-proficiency ones mainly because their management and monitoring of reading was guided more by the goals they have set themselves than by the tests and assignments they were supposed to write.

\section{Introduction}

The importance of the reading skill in academic contexts has made it imperative for second language researchers to find out how students can be helped to deal with academic reading and writing tasks. Researchers have explored reading strategies that first and second language (L1 and L2) readers used to compensate for their lack of reading proficiency and what they did to increase reading comprehension (Carell, Pharis \& Liberto 1989; Mokhtari \& Sheorey 2002). Research also shows that there is a positive relationship between students' metacognitive awareness of reading processes and their ability to read and excel academically (Alderson 1984; Carrell 1991; Chan 2003; Mokhtari \& Sheorey 2002; Singhal 2001 ).

To that end, this study explores the awareness level of the University of Botswana students as to the use of metacognitive reading strategies. Furthermore, it familiarises us with the reading proficiencies of the Botswana L2 speakers of the English language, and informs us about the relationship between these students' reading proficiencies and their use of metacognitive reading strategies. According to Chan (2003:177):

[p]oor readers score lower than good readers in using all reading strategies, and especially in using sophisticated cognitive and metacognitive strategies ... The awareness and the use of cognitive and metacognitive strategies are closely related to the efficiency of the reading process.

\section{Theoretical framework}

Much of the early ESL reading research provided a theoretical background for studies in this area. For example, psycholinguistic models of L2 reading, such as those by Clarke and Silberstein (1977) and Coady (1979), described reading as an active process of text comprehension in which the reader uses background knowledge and appropriate strategies, such as previewing text, using contextual clues or making inferences. More recent models (Carrell 1988; Pritchard 1990) have theorised that reading is an interactive process in which readers use their prior knowledge and cultural background to interact with the text. This study follows Flavell's (1979) submission that reading is a cognitive enterprise which occurs as a result of interaction among the reader, the text, and the context in which the reading takes place. Furthermore, the reader uses metacognitive knowledge and evokes conscious and deliberate strategies to comprehend the text. According to Paris and Jacobs (1984:2083), 'Skilled readers often engage in deliberate activities that require planful thinking, flexible strategies, and periodic self-monitoring ... novice readers often seem oblivious to these strategies and the need to use them.' 
Metacognitive strategies are defined by Singhal (2001:156) as:

... behaviors undertaken by the learners to plan, arrange, and evaluate their own learning. Such strategies include directed attention and self-evaluation, organization, setting goals and objectives, seeking practice opportunities, and so forth. In the context of reading, self-monitoring and correction of errors are further examples of metacognitive strategies.

The definition and classification of reading strategies is also conceptualised in terms of the classification of language learning strategies by Oxford (1990) as cognitive, metacognitive, memory, affective, compensation and social strategies. In line with Singhal (2001), within the broader context of general reading strategies, the specific reading strategies are defined as:

- Cognitive reading strategies used to manipulate the language that include note-taking, summarising, paraphrasing, predicting, analysing and using context clues.

- Memory reading strategies, which are techniques used to assist the learner to recall information, such as word association and semantic mapping.

- Compensation reading strategies, such as 'inferencing', and guessing while reading, which can assist the learner in making up for reading deficiencies.

- Affective reading strategies, which include selfencouraging behaviour to lower anxiety, such as rewarding oneself for reading efficiently.

- Social reading strategies, involving collaborating with peers, for example, to ask questions, seek help or correction and to get feedback while reading.

\section{Justification}

Exploring the use of metacognitive reading strategies and their relation to proficiency is of interest in this study because it reduces the dearth of research in this area. According to Singhal (2001), empirical investigations into metacognitive reading strategies used by successful and unsuccessful L2 learners are less common than studies on teaching L2 learners to use a variety of language strategies to read better. Carrell (1989) suggests that additional studies of metacognitive factors in L2 reading are needed. In the Botswana ESL context, no studies have investigated the use of reading strategies and their relationship to reading proficiency. The closest is an exploratory study by Magogwe (2005) dealing with language learning strategies of Botswana students. Exploring the metacognitive awareness of reading strategies should have important implications for developing the Botswana students' reading efficiency. That the University of Botswana First Year students are required to study the Communication and Academic Literacy Skills courses, where reading is one of the skills taught, suggests that the students' reading of academic materials should be improved. According to Mokhtari \& Sheorey (2002:3), interventions that help students to increase awareness of their metacognitive reading strategies increase their level of engagement when reading English texts. They further posit that it is this awareness that distinguishes skilled from unskilled readers. In light of the above, this study asks the following questions:
1. What are the self-reported reading proficiencies of the University of Botswana students?

2. Are the University of Botswana students aware of their metacognitive reading strategies?

3. What kind of metacognitive reading strategies are frequently used?

4. Is there a difference in metacognitive awareness of reading strategies used by high- and low-proficiency students respectively?

\section{Methodology Participants}

Participants of this study were 104 First Year students from the Social Sciences Faculty in the University of Botswana, studying Communication and Academic Literacy Skills. These students belong to three Communication and Academic Literacy classes taught by the researcher. Seventy- two point eight percent of these were female and $26.2 \%$ male. However, it should be noted that gender was not the main focus of this study. The students were selected through convenience sampling. This is a non-probability sampling technique where subjects are selected on basis of their accessibility and proximity to the researcher. The researcher did not consider selecting subjects that were representative of the entire student population. Only students who were willing to complete the questionnaire participated in the study. The University of Botswana is the oldest and biggest institution of higher learning in Botswana in terms of student population. At this institution, like other institutions of learning in Botswana, English is the official language of instruction and reading materials are written in English. Botswana is located in Southern Africa, neighboured respectively by South Africa to the east and south, Namibia to the west, and Zimbabwe to the north. The participants came from different socio-cultural backgrounds, but all shared the Botswana nationality. Also, their reading aptitude could be regarded as similar if we accept the fact that they have all qualified for admission into the University of Botswana, where entry requirements for the Social Sciences are higher than those of other faculties such as Humanities and Education.

\section{Data collection}

Triangulation was used to buttress the findings of this study. Quantitative data were collected using a questionnaire. Qualitative data were collected using the semi-structured interview technique. McEwan and McEwan (2003) define triangulation as the use of various data-gathering methods. According to Maree (2008:39), 'the purpose of triangulation is to obtain complementary quantitative and qualitative data on the same topic and bring together the different strengths of the two methods'.

\section{The instrument}

The Survey of Reading Strategies Questionnaire (SORS) developed by Mokhtari and Sheorey (2002) was used to collect data. The SORS was used so that the students could indicate the extent to which they used metacognitive reading 
strategies. According to Mokhtari and Sheorey (2002), the SORS was designed for use with ESL students in high schools, colleges and universities; has been field-tested, and has demonstrated reliability and validity. According to Mokhtari and Sheorey (2002), the internal consistency reliability coefficient (as determined by Cronbach's alpha) was 0.92 for the Global Reading Strategies, 0.79 for the Problem Solving Strategies, and 0.87 for the Problem Solving Strategies. For this reason, the author found it relevant for assessing University of Botswana ESL students' awareness of metacognitive reading strategies. The SORS is a 30-item questionnaire using a 5-point Likert Scale. A score of 5 meant that the student always used a strategy; 4 meant it was used most of the time; 3 meant sometimes using the strategy; 2 meant using the strategy occasionally; and 1 meant the student never used the strategy (Mokhtari \& Sheorey 2002:4).

The SORS comprised three subscales: Global Reading Strategies or GLOB, Problem Solving Strategies or PROB, and Support Reading Strategies or SUP, as presented in Tables 2, 3 and 4 respectively. According to Mokhtari and Sheorey (2002), students use Global Reading Strategies to work with text directly or to manage and monitor their reading intentionally and carefully. Problem Solving Strategies are used for solving problems of understanding that arise during the reading of a text. Support Reading Strategies are used as basic mechanisms intended to aid reading comprehension, for example through note-taking, underlining and highlighting textual information (Mokhtari \& Sheorey 2002).

\section{Procedure}

The researcher administered the questionnaires to his three classes as indicated earlier. The students were asked to circle the number that applied to them indicating the frequency with which they used the reading strategy described in the statement. The students took a maximum of 20 minutes to complete the questionnaire in class under the researcher's supervision. Clarification of questions were made by the researcher where and when necessary.

\section{Questionnaire analysis}

Following Mokhtari and Sheorey's (2002) analysis of the SORS, frequencies were counted and averaged to determine the types of strategies used by the students. The higher the averages the more frequently the student used the strategy concerned. To explain this further, individual scores from each student were added up to obtain a total score for each subscale and for the entire instrument. The scores were interpreted using the interpretation key provided by Mokhtari and Sheorey (2002). Based on Oxford and BurryStock (1995) for general learning strategy usage, Mokhtari and Sheorey identified high strategies as scoring 3.50 or higher, medium 2.5-3.49, and low 2.49 and below. The usage levels provided a convenient standard for interpretation of the score averages.

\section{Interviews}

Nine students from those who completed the questionnaire were selected for the oral interview. Only those students who had rated their reading proficiency as either very good/ excellent or poor were interviewed. This particular selection was done for no other reason than to reduce the number of interviewees. According to Guilfoyle and Hill (2002), the number of interviewees need not be a problem because the sampling is not done in order to get enough people, but to collect sufficient data. In the discussion section, very good or excellent interviewees are referred to as 'proficient' and the poor ones as 'not proficient'. The content of the interviews, as well as the situation in which the strategies were used, were transcribed and analysed. The interviewees were asked to explain the purpose of their reading and to say what they did to improve understanding while reading. They were also asked to explain what they did if the text they were reading was difficult, and to say what they did when they lost concentration. Furthermore, the interviewees were asked to explain what they did to decide on the text to read, and to clarify how they decided on the amount of text to read. They were also asked to elucidate on how they decided which information is or is not important when reading. They were also asked to explain what they did if they did not understand the text they were reading. Finally, they were asked to explain at what point they checked their understanding of the reading.

\section{Results and discussion}

The results of this study are presented first for the SORS questionnaire and next for the structured interviews. The first research question of this study sought to examine the selfreported reading proficiencies of the University of Botswana ESL students in the Social Sciences. The results show that $15 \%$ rated their reading as excellent, $44 \%$ as good, $39 \%$ as moderate, and $2 \%$ as poor. It was explained to the students that reading proficiency meant how good or bad they thought they were at reading academic materials. This means that the majority of the students in this study (59\%) thought they were proficient in reading while $41 \%$ were either average or poor. It is not surprising that almost all the students in this study claimed to be proficient in reading, probably because they had performed well at senior secondary school. For one to be admitted into the Social Sciences in the University of Botswana one has to have passed English with the minimum of a credit pass. Social Science entry requirements are usually higher than those of Faculties such as Education and Humanities. For that reason, one could conclude that Social Science students were generally more competent readers of academic materials.

The second research question sought to explore the students' overall use of metacognitive reading strategies. The overall average score for the SORS in this study $(\mathrm{M}=3.57)$ is high following Mokhtari and Sheorey's (2002) levels of use as described above. As previously stated, these levels are based 
on Oxford and Burry-Stock's (1995) averages for measuring general language learning strategies. Overall, $90.3 \%$ of the students reported high to medium metacognitive reading strategy use (40.8\% high strategy use and $49.5 \%$ medium), and only $9.7 \%$ low use (see Table 1 ). The findings of this study are consistent with those of Mokhtari and Sheorey. The Social Science students were generally capable of effectively planning, monitoring and evaluating their own reading.

The third research question examined the kind of metacognitive reading strategies frequently used by all the students. This was done by obtaining the averages of the subscales (Global, Problem Solving and Support Strategies) in the SORS. The scores for the respective subscales were added up and divided by the number of items in each. The average for each subscale in the questionnaire represented the mean frequency with which the learners used a given subscale of strategies when reading academic materials. The SORS results demonstrated that $29.2 \%$ of the students reported high use $(\mathrm{M}=3.97)$ of Problem Solving Reading Strategies. As for the Global Reading Strategies, 40.8\% reported medium use $(\mathrm{M}=3.42)$, and similarly medium use of Support Reading Strategies was reported by $28.4 \%$ of the students. These findings are interesting because they suggest that, although the students reported high use of overall strategies, they still needed to improve their use of specific strategies as shall be seen below. For this reason they could not, therefore, be regarded as being completely effective readers of academic materials.

Considering the kind of Problem Solving Reading Strategies, the students claimed to have no problems with solving reading difficulties. They indicated that when the text is difficult, they re-read it (Strategy 25, M = 4.47); paid close attention to it (Strategy 14, M = 4.28); slowly and carefully tried to understand the text (Strategy 7, M = 4.11), and tried to regain concentration (Strategy 9, $\mathrm{M}=4.12$ ). They also, interestingly, controlled their reading speed (Strategy 11, $\mathrm{M}=3.93$ ); and used visual, guessing, and thinking skills to solve reading problems (Strategies $19, \mathrm{M}=3.76 ; 28$, $\mathrm{M}=3.65$; and 16, $\mathrm{M}=3.58$ ). See Table 2 for the Problem Solving Strategies subscale. All the above Problem Solving strategies are reported at high use.

Regarding Support Reading Strategies, the students reported high use of Strategy $10(\mathrm{M}=4.08)$, Strategy 2 $(\mathrm{M}=3.78)$, and Strategy $18(\mathrm{M}=3.76)$. The students used these strategies to underline and circle information, take notes and paraphrase or restate ideas in their own words. See Table 3 for more details on the Support Reading Strategies. Given the above, these students qualified as proficient readers because proficient readers aid reading through note-taking, underlining and highlighting textual information (Mokhtari \& Sheorey (2002). To further support the argument that the students were very skillful readers, they reported lower medium use of thinking about information in both English and mother tongue, and translating English into their native languages. In Botswana, students are generally discouraged by teachers with regard to using their mother tongue in
TABLE 1A: Overall strategy usage on the SORS for Botswana students.

\begin{tabular}{lccc}
\hline Usage & Male & & Female \\
& Low & & $\boldsymbol{N}$ \\
Medium & $2.00-2.53$ & & 10 \\
High & $3.00-3.47$ & 44 \\
& $2.60-2.93$ & 7 \\
\hline
\end{tabular}

Source: Created by author for paper

SORS, Survey of Reading Strategies; M, mean; N, number.

TABLE 1B: Overall strategy usage on the SORS for Botswana female students.

\begin{tabular}{lcc}
\hline Female & \multicolumn{2}{c}{ Total } \\
\cline { 2 - 3 } & $\boldsymbol{N}$ & $\mathbf{\%}$ \\
\hline Low & 10 & 9.7 \\
Medium & 51 & 49.5 \\
High & 42 & 40.8 \\
\hline
\end{tabular}

Source: Created by author for paper

SORS, Survey of Reading Strategies.

TABLE 2: Problem Solving Strategies.

\begin{tabular}{llcc}
\hline Strategy & Problems solving & M & SD \\
\hline 7 & $\begin{array}{l}\text { I read slowly and carefully to make sure I } \\
\text { understand what I am reading. }\end{array}$ & 4.11 & 0.84 \\
\hline 9 & $\begin{array}{l}\text { I try to get back on track when I lose } \\
\text { concentration. }\end{array}$ & 4.12 & 0.94 \\
\hline 11 & $\begin{array}{l}\text { I adjust my reading speed according to what I } \\
\text { am reading. }\end{array}$ & 3.93 & 1.00 \\
\hline $14 \quad \begin{array}{l}\text { When text becomes difficult, I pay closer } \\
\text { attention to what I am reading. }\end{array}$ & 4.28 & 0.70 \\
\hline $16 \quad \begin{array}{l}\text { I stop from time to time and think about what } \\
\text { I am reading. }\end{array}$ & 3.58 & 1.10 \\
\hline 19 & $\begin{array}{l}\text { I try to picture or visualise information to help } \\
\text { remember what I read. }\end{array}$ & 3.76 & 1.10 \\
25 & $\begin{array}{l}\text { When text becomes difficult, I re-read it to } \\
\text { increase my understanding. }\end{array}$ & 4.47 & 0.72 \\
\hline 28 & $\begin{array}{l}\text { When I read, I guess the meaning of unknown } \\
\text { words or phrases. }\end{array}$ & 3.65 & 1.19 \\
\hline Overall Mean & 3.97 & - \\
\hline
\end{tabular}

Source: Created by author for paper

$\mathrm{SD}$, standard deviation; M, mean.

TABLE 3: Support Reading Strategies.

\begin{tabular}{|c|c|c|c|}
\hline Strategy & Support Reading Strategies & $M$ & SD \\
\hline 2 & $\begin{array}{l}\text { I take notes while reading to help me } \\
\text { understand what I read. }\end{array}$ & 3.78 & 1.14 \\
\hline 5 & $\begin{array}{l}\text { When text becomes difficult, I read aloud to } \\
\text { help me understand what I read. }\end{array}$ & 3.62 & 1.50 \\
\hline 10 & $\begin{array}{l}\text { I underline or circle information in the text to } \\
\text { help me remember it. }\end{array}$ & 4.08 & 1.10 \\
\hline 13 & $\begin{array}{l}\text { I use reference materials (e.g. a dictionary) to } \\
\text { help me understand what I read. }\end{array}$ & 3.38 & 1.10 \\
\hline 18 & $\begin{array}{l}\text { I paraphrase (restate ideas in my own words) to } \\
\text { better understand what I read. }\end{array}$ & 3.76 & 1.01 \\
\hline 22 & $\begin{array}{l}\text { I go back and forth in the text to find } \\
\text { relationships among ideas in it. }\end{array}$ & 3.43 & 1.15 \\
\hline 26 & $\begin{array}{l}\text { I ask myself questions I would like the text to } \\
\text { answer. }\end{array}$ & 3.37 & 1.25 \\
\hline 29 & $\begin{array}{l}\text { When reading, I translate from English into my } \\
\text { native language. }\end{array}$ & 2.53 & 1.37 \\
\hline 30 & $\begin{array}{l}\text { When reading, I think about information in } \\
\text { both English and my mother tongue. }\end{array}$ & 2.87 & 1.41 \\
\hline \multicolumn{2}{|c|}{ Overall Mean } & 3.42 & - \\
\hline
\end{tabular}

Source: Created by author for paper

$\mathrm{SD}$, standard deviation; $\mathrm{M}$, mean

schools across all levels of education, because English is the official language. In addition, these students reported medium use of reference materials, and asking themselves questions. It could be argued that these students were in the process of acquiring research skills, which include use of a variety of resources, because they were still at the beginning stages of academics. 
As far as Global Reading Strategies are concerned, these students reported high use of reading with a purpose, using personal experiences and background knowledge, and reading closely to decide what to take and what to ignore. However, it is important to note that these students reported medium use of Strategy $24(\mathrm{M}=3.23)$ where they guessed the content of the text when they read, and also medium use of Strategy $27(\mathrm{M}=3.39)$ where they checked to see if their guesses about the text were right or wrong. It is also worth noting that in this subscale, the students also reported medium use of important strategies such as Strategy $20(\mathrm{M}=2.96)$, Strategy $15(\mathrm{M}=2.82)$, and Strategy 21 $(\mathrm{M}=3.14)$ where they used typographical features such as bold face and italics to identify key information, tables, figures, and pictures in the text to increase understanding; and to critically analyse and evaluate the information presented in the text. They also reported medium use of reviewing text by noting characteristics such as its length and organisation (Strategy $8, M=2.65$ ). See Table 4 for more details of the Support Reading Strategies. As already noted, in the Problem Solving strategy subscale the students reported high use of guessing the meaning of unknown words and phrases, and from time to time thinking about what they were reading. Here in the Global Reading scale, however, at a medium level, the students guessed the content of the text, and also checked to see if their guesses were right or wrong. It could be argued that the students' guessing and thinking skills were limited to deducing vocabulary meanings rather than digging deep into the gist of the text to infer, interpret and analyse it. In other words, the Social Science students were still not yet proficient in terms of critically interrogating the subject matter of academic texts. Furthermore, they still lacked understanding of the role of length and organisation, especially when summarising academic materials.

The fourth research question compared the strategy used by high- and low-proficiency students respectively. The highest overall mean score for strategy use is that of Excellent students $(M=3.82)$, ironically followed by Poor students $(M=3.68)$, then Good students $(M=3.56)$, and Moderate proficiency students $(M=3.46)$ (See Table 5$)$. These findings show that the students across all proficiency levels recorded high use of metacognitive strategies. In other words, the difference between these students was not that great. Despite the small differences, there are equally important differences to note in the results. Students across different proficiency levels mostly recorded medium to high use of strategies. Excellent students used Strategy 4 (I take an overall view of the text to see what it is about before reading it) at a high level compared to students of other proficiencies who used it at a medium level. The same applies to Strategy 24 (I try to guess what the content of the text is about when I read), and Strategy 26 (I ask myself questions I would like the text to answer). This is consistent with Pressley and Afflerbach's (1995:4) findings that:

more proficient readers overview text before reading it; employ context clues such as titles, subheading, and diagrams; look for important information while reading and pay greater attention to it ... ; attempt ... to understand the text as a whole, activate
TABLE 4: Gobal reading strategies.

\begin{tabular}{|c|c|c|c|}
\hline Strategy & Global reading strategies & $M$ & SD \\
\hline 1 & I have a purpose in mind when I read. & 4.29 & 0.83 \\
\hline 3 & $\begin{array}{l}\text { I think about what I know to help me understand } \\
\text { what I read. }\end{array}$ & 3.91 & 0.96 \\
\hline 4 & $\begin{array}{l}\text { I take an overall view of the text to see what it is } \\
\text { about before reading it. }\end{array}$ & 3.39 & 1.19 \\
\hline 6 & $\begin{array}{l}\text { I think about whether the content of the text fits } \\
\text { my reading purpose. }\end{array}$ & 3.89 & 1.02 \\
\hline 8 & $\begin{array}{l}\text { I review the text first by noting its characteristics } \\
\text { like length and organisation. }\end{array}$ & 2.65 & 1.30 \\
\hline 12 & $\begin{array}{l}\text { When reading, I decide what to read closely and } \\
\text { what to ignore. }\end{array}$ & 3.59 & 0.98 \\
\hline 15 & $\begin{array}{l}\text { I use tables, figures, and pictures in text to } \\
\text { increase my understanding. }\end{array}$ & 2.82 & 1.43 \\
\hline 17 & $\begin{array}{l}\text { I use context clues (evidence or hints from } \\
\text { background knowledge) to help me better } \\
\text { understand what I am reading. }\end{array}$ & 3.56 & 1.11 \\
\hline 20 & $\begin{array}{l}\text { I use typographical features like bold face and } \\
\text { italics to identify key information. }\end{array}$ & 2.96 & 1.30 \\
\hline 21 & $\begin{array}{l}\text { I critically analyse and evaluate the information } \\
\text { presented in the text. }\end{array}$ & 3.14 & 1.15 \\
\hline 23 & $\begin{array}{l}\text { I check my understanding when I come across } \\
\text { new information. }\end{array}$ & 3.68 & 0.99 \\
\hline 24 & $\begin{array}{l}\text { I try to guess what the content of the text is } \\
\text { about when I read. }\end{array}$ & 3.23 & 1.23 \\
\hline 27 & $\begin{array}{l}\text { I check to see if my guesses about the text are } \\
\text { right or wrong. }\end{array}$ & 3.39 & 1.28 \\
\hline \multicolumn{2}{|c|}{ Overall Mean } & 3.42 & - \\
\hline
\end{tabular}

Source: Created by author for paper

$\mathrm{SD}$, standard deviation; $\mathrm{M}$, mean.

and use prior knowledge to interpret text, ... , attempt to infer information from the text, ... monitor text comprehension, identify or infer main ideas, use strategies to remember text (paraphrasing, repetition, making notes, summarizing, selfquestioning, etc), ... recognize text structure, change reading strategies when comprehension is perceived not be proceeding smoothly and so forth.

Interestingly, excellent students recorded low use of strategy 8 (I review the text first by noting its characteristics like length and organization) compared to students from other proficiency levels' medium recording. Excellent students probably felt that they could handle a text no matter how long it was and how it was organised. It is also interesting to note that Strategy 29 (When reading, I translate from English into my native language) was recorded as high only by poor students, whereas moderate and good students recorded it as low and excellent students as medium.

A thorough content analysis was carried out on all transcripts of the semi-structured interviews. The main objective in conducting the interviews was to identify the situations where the subjects used metacognitive reading strategies. Firstly, the students were asked to state their reading purpose. Interestingly, low-proficiency students seemed to read academic materials mainly to gain knowledge, pass tests, get a degree and find a better job. Of the four, only one said they read'... something that interests me e.g. in the newspaper. Otherwise I don't read things that do not interest $m^{\prime}$. On the other hand, high-proficiency students read for more meaningful purposes and managed their reading quite evidently. They set themselves reading goals; felt bad when they were not reading, and were motivated to read and to remember things that were meaningful to them. For example, this is what they said: 
TABLE 5: Strategy use by proficiency.

\begin{tabular}{|c|c|c|c|c|c|c|c|c|}
\hline \multirow[t]{2}{*}{ Strategies } & \multicolumn{2}{|c|}{ Poor } & \multicolumn{2}{|c|}{ Moderate } & \multicolumn{2}{|c|}{ Good } & \multicolumn{2}{|c|}{ Excellent } \\
\hline & M & $N$ & M & $N$ & M & $N$ & M & $N$ \\
\hline $\mathrm{H}$ & $3.50-5.00$ & 24 & $3.54-4.46$ & 14 & $3.52-4.45$ & 17 & $3.67-4.60$ & 24 \\
\hline M & $2.50-3.00$ & 6 & $2.51-3.46$ & 15 & $2.70-3.48$ & 12 & $2.73-3.20$ & 5 \\
\hline L & - & 0 & 2.47 & 1 & 2.32 & 1 & 2.47 & 1 \\
\hline Total & & 30 & & 30 & & 30 & & 30 \\
\hline
\end{tabular}

Source: Created by author for paper

$\mathrm{M}$, mean; $N$, number.

Student C: Yes. I read every day practically. Even if I don't have any objectives I just go to the library to read. I feel bad when I am not reading. I am self-motivated. Most of the time I read internet, webCT and text books. I also read current news on Yahoo.

Student B: Yes. For instance when I go into the library with a goal to achieve otherwise I don't leave until I have reached my goal.

Student E: Yes. To remember in the long run or in future. I don't read for tests.

Student F: Yes of course. So that what I am reading can be meaningful to me. At the end of the day I achieve something.

Student G: Yes, I do. I enjoy reading a lot. It is my passion. I like to improve my vocabulary. It stimulates my thinking. I try and figure out words from context.

Secondly, they were asked to describe what they did whilst reading to help their understanding of the academic material they were reading. Here, too, both low-and highproficiency students used techniques that could support their understanding of academic materials. However, highproficiency students seemed to have an edge over lowproficiency ones because they went beyond taking notes to improve their reading. Low-proficiency students read and answered questions; made rough notes without referring to the text, and summarised the notes, whereas high-proficiency students did more by using pictures, graphs, acronyms and so on to enhance their understanding. Specifically this is what high-proficiency students say:

Student B: I take notes. At times I do pictorial representations depending on what I am reading e.g. when I read Economics I use graphics to enhance my understanding.

Student C: I write down on paper whatever I am reading. I read it many times. I read a maximum of 3 hours a day.

Student E: I read and close the book and rewrite what I was reading to check my understanding. Sometimes I spell out what I am reading. Sometimes I use acronyms. Sometimes I go out to explain to someone what I am reading.

Student F: I listen to music while reading. I take breaks and watch comedy or movie.

Student G: I always have a dictionary. Also, if I am reading notes I research on the internet. I ask people. I ponder.

Thirdly, the students were asked to explain what they did when the text they were reading became difficult. Lowproficiency students mainly postponed their reading and sometimes asked other students or lecturers for help. On the other hand, high-proficiency students consulted reference materials such as a dictionary; took a break; asked for help; and avoided thinking too much about their failure.
Fourth, they were asked to explain how they decide on which text to read. Here, both low- and high-proficiency students read what they found to be interesting or needed their attention, and they both used the study timetable to organise their reading.

Fifth, they were asked to say what they did when they lost concentration. Both low- and high-proficiency students stopped reading when they couldn't concentrate. Notably, low-proficiency students became intimidated and '[s] ometimes I panic and leave and do nothing,', '[s]ometimes I give up. I'll probably like study tomorrow or something.' High-proficiency students, on the other hand, looked for alternatives to allow themselves to relax or refresh, and would later tackle the task head on. For instance they say:

Student B: I try to relax for 10-15 minutes. I leave whatever I am reading and read or do something else.

Student C: I listen to music. Mostly I study listening to music, it doesn't distract me.

Student E: I take time out and read later on.

Student F: I watch a movie or I read something that will motivate me to go back and read what I was reading. Sometimes I think of the purpose of the subject and its benefits.

Student G: That happens a lot. I try to come back and focus on the task at hand. Sometimes I lose concentration. When I have over-read I leave it for a while and come back later.

Sixth, the students were asked how they decided on the amount of text to read. For both low- and high-proficiency students it largely depended on whether they had achieved their reading objectives. Both of them also decided on the basis of their concentration span.

Seventh, the students were asked to explain what they did to decide as to which information is or is not important when reading. In both cases what the students read was determined by the topic they were supposed to read; test and assignment dates; and the timetable.

Eighth, the students were asked to describe what they did if they did not understand the text they were reading. Lowproficiency students seemed to depend more on asking for help when they did not understand the text. Only one of them (Student D) revisited the text as he said, 'I revisit the text. I look for definitions of words'. On the contrary, highproficiency students were more self-reliant. Specifically they said: 
Student B: I just leave it and read some other simpler text to understand.

Student C: I postpone it. I read many times. But eventually I leave it until the following day.

Student E: Sometimes I spell it out, take time out and revisit it. Sometimes I consult.

Student F: If it's a subject I do with other people I can ask them. I can discuss with others. I can google it etc. just so that I understand. Some people have more experience than I do on that particular subject.

Finally, they were asked to identify the point at which they checked understanding of their reading. They stopped at the end of the reading task. Again they checked their understanding either by way of asking questions or by testing themselves.

\section{Implications}

The majority of Social Science students reported in this study were quite capable of using Global Reading Strategies to read academic materials such as books and journals, but they need to be assisted to do so substantially. Specifically, the students should be helped where they reported medium use of strategies. Lecturers should emphasise skills such as guessing and evaluating content; using typographical features; summarising text; using reference materials; and interrogating text. Typically, lecturers should analyse the strategies they should teach and find out in which contexts these strategies should be applied. They should also provide students with opportunities to practise these strategies. According to Mokhtari and Sheorey (2002:3), teachers can use a combination of direct and indirect strategy training.

\section{Limitations}

This study is limited by the relatively small sample size used for proficiency. A more reliable larger sample should be used in future to make the results more reliable. Also, a study like this should be replicated with different learners from different Faculties in the University. Self-rating of proficiency may also be limiting in that a more reliable proficiency test was not used in this study.

\section{Conclusion}

This study has provided a picture of the strategies preferred by students in the Social Sciences at the University of Botswana. The findings reported high use of the metacognitive reading strategies consistent with Mokhtari and Sheorey's (2002) guidelines. However, the Communication and Academic Literacy Skills Unit and sister departments of the University of Botswana should assist students to become more aware of and increase their metacognitive reading strategies. According to Davies (1995), metacognitive strategies involve awareness, reasoning and conscious thought processes about the text read and the understanding gained from it. This study has also helped us to compare strategies used by students across all proficiency levels. More proficient students reported strategies that showed more meaningful and purposeful reading than just reading for tests and assignments. However, the proficiency differences were not that important because these students generally belong to the same bracket in terms of academic competence. The findings of this study have contributed to the growth of research in this area by confirming indeed that more proficient students use high metacognitive strategies. This study recommends additional reading strategy research to compare students from different faculties and genders, especially in the ESL context. It may be necessary to follow up the cohort of students used in this study at a later stage to gain more insight into the strategies they use as they progress to higher levels of education. This study supports Carrell's (1989) recommendation that additional L2 studies should establish the relationship between students' reading abilities and reading performance on a wide variety of tasks. Finally, metacognitive reading strategies should be regarded as an opportunity to 'provide students with knowledge and confidence that enables them to manage their own learning and empowers them to be inquisitive and zealous in their pursuits' (Paris \& Winograd 1990:22).

\section{Acknowledgements}

I would like to thank my COM 151 class of 2012 who agreed to participate in this study. My sincere gratitude goes to Dr Tsaone Mokgwathi who, despite her busy schedule, agreed to edit this article. Last but not least, I thank the Communication and Study Skills Unit lecturers who attended my seminar in which I presented this article for their useful comments. Finally, thank you to my God Jehovah.

\section{Competing interests}

The author declares that he has no financial or personal relationship(s) which may have inappropriately influenced him in writing this paper.

\section{References}

Alderson, J.C., 1984, 'Reading in a foreign language: A reading problem or a language problem?', in J.C. Alderson \& A. Uruquhart (eds.), Reading in a Foreign Language, pp. 1-227, Longman, New York.

Carrell, P., 1988, 'Interactive text processing: implications for ESL/second language reading. Classrooms', in P. Carrell, J. Devine \& D. Eskey (eds.), Interactive Approaches to Second Language Reading, pp. 239-259, Cambridge University Press, New York. http://dx.doi.org/10.1017/CBO9781139524513.023

Carrell, P.L., 1989, 'Metacognitive Awareness and Second Language Reading', The Modern Language Journal 73(2), Summer, 121-134. http://dx.doi. org/10.1111/j.1540-4781.1989.tb02534.x

Carrell, P. L., 1991, 'Second language reading ability or language proficiency?', Applied Linguistics 12, 159-179. http://dx.doi.org/10.1093/applin/12.2.159

Carrell, P.L., Pharis, B. \& Liberto, J., 1989, 'Metacognitive strategy training for ESL reading', TESOL Quarterly 23, 647-678. http://dx.doi.org/10.2307/3587536

Chan, D.W., 2003, 'Reading strategy use and motivation among Chinese good and poor readers in Hong Kong', Journal of Research in Reading 26(2), 177-190. http://dx.doi.org/10.1111/1467-9817.00195

Clarke, M.A. \& Silberstein, S., 1977, 'Toward a realization of psycholinguistic principles for the ESL reading class', Language Learning 27, 134-154. http://dx.doi. org/10.1111/j.1467-1770.1977.tb00297.x

Coady, J., 1979, 'A psycholinguistic model of the ESL reader', in R. Mackay, B. Barkman \& R. Jordan (eds.), Reading in a Second Language, pp. 5-12, Newbury House, Rowley, MA. 
Davies, F., 1995, Introducing Reading, Penguin Books, London.

Flavell, J., 1979, 'Metacognition and cognitive monitoring: a new era of cognitivedevelopment inquiry', American Psychologist 34, 906-911. http://dx.doi. org/10.1037/0003-066X.34.10.906

Guilfoyle, A. \& Hill, S., 2002, 'Interviews in Qualitative Research: A resource Kit for Beginners', viewed n.d., from http://www.ecu.edu.au.

Magogwe, J., 2005, 'Language Learning Strategies of Botswana Students: An Exploratory Study', unpublished PhD Thesis, Faculty of Education, Edith Cowan University.

Maree, K., 2008, First Steps in Research, (4th edn.), Van Schaik Publishers, Pretoria.

McEwan, E. \& McEwan, P., 2003, Making Sense of Research, Sage Publications Ltd, London.

Mokhtari, K. \& Sheorey, R., 2002, 'Measuring ESL students' awareness of reading strategies', Journal of Development Education 25(3), 2-10.

Oxford, R.L., 1990, Language learning strategies. What Every Teacher Should Know, Heinle \& Heinle Publishers, Boston. http://dx.doi.org/10.1016/0346251X(94)00047-A
Oxford, R. \& Burry-Stock, J.A., (1995), 'Assessing the use of language learning strategies worldwide with the ESL/EFL version of the strategy inventory for language learning (SILL)', System 23(1), 1-23.

Paris, S.G. \& Jacobs, J., 1984, 'The benefits of informed instruction for children's reading awareness and comprehension skills', Child Development 55, 2083-2093. http://dx.doi.org/10.2307/1129781

Paris, S.G. \& Winograd, P., 1990, 'How metacognition can promote academic learning and instruction', in B.F. Jones \& L. Idol (eds.), Dimensions of Thinking and Cognitive Instruction, pp. 15-51, Erbaum, Hillsdale, N.J.

Pressley, M. \& Afflerbach, P., 1995, Verbal Protocols of Reading: The Nature of constructively responsive reading, Erlbaum, Hillside, N.J.

Pritchard, R., 1990, 'The effects of cultural schemata on reading process strategies', Reading Research Quarterly 25, 273-295. http://dx.doi.org/10.2307/747692

Singhal, M., 2001, 'Reading, proficiency, reading strategies, metacognitive awareness and L2 learners', The Reading Matrix 1(1), 1-23, available from www. readingmatrix.com. 